\title{
An escalating trade in orchid tubers across Tanzania's Southern Highlands: assessment, dynamics and conservation implications
}

\author{
Tim R. B. Davenport and Henry J. Ndangalasi
}

\begin{abstract}
Kinaka or Chikanda has been eaten by people in parts of Zambia, northern Malawi and south-western Tanzania for hundreds of years. Prepared from the boiled root tubers of terrestrial orchids, and principally from species of the genera Disa, Habenaria and Satyrium, it was formerly a traditional village delicacy and did not pose a threat to orchid populations. However, the past decade has witnessed a dramatic rise in demand in Zambia, particularly in urban areas. This has triggered a burgeoning commercial market and has now prompted traders to seek tubers from Tanzania's Southern Highlands, an important centre of endemism for upland species of orchid. The resulting cross-border trade, its dynamics and the implications for Tanzanian orchids are reported here for the first time. Whilst all orchid species are in CITES Appendix II, collectors are currently
\end{abstract}

harvesting between 2.2 and 4.1 million tubers per year for export to, and consumption in, neighbouring Zambia. As many as 85 species may be at risk from this trade, and there is evidence that large areas in Ufipa, Mbeya and Kipengere have already been stripped of their orchids. A decline in traditional Tanzanian consumption of Kinaka seems to be having little or no impact on harvesting volumes. Orchid collection across the Southern Highlands is now escalating at a rate that may be far from sustainable. The consequences for Tanzanian biodiversity and for one of Africa's most important areas for orchids are profound.

Keywords CITES, orchids, Southern Highlands, Tanzania, trade, Zambia.

\section{Introduction}

The harvesting of orchid tubers for food has a long history in the culture of many ethnic groups. This is particularly so in Zambia, where the resulting dish, known there as Chikanda, is likened to a meatless sausage. After harvesting, tubers are dried, pounded, boiled with baking soda or wood ash, and then served with a staple. Alternatively, the mixture is cooled and squeezed to remove water for storage (Mwizenge, 1997; Bingham, 1999). The tubers belong to a variety of terrestrial orchid species mostly of the genera Disa, Satyrium and Habenaria (Bingham, 1999, 2000). Originally a rural delicacy, Chikanda is now widely consumed throughout Zambia, particularly in urban areas, where it is often advertised as 'African prunes'. Its popularity has grown and demand for the tubers has increased accordingly. However, although traditional harvesting was largely sustainable (Bingham, 1999, 2000), collection for commercial purposes is probably not and many areas of Zambia now report that their resources are depleted

Tim R. B. Davenport (Corresponding author) Wildlife Conservation Society, P.O. Box 1475, Mbeya, Tanzania. E-mail: trbd@twiga.com

Henry J. Ndangalasi Department of Botany, University of Dar es Salaam, P.O. Box 35060, Dar es Salaam, Tanzania. E-mail: hjndangalasi@yahoo.com

Received 26 November 2001. Revision requested 13 May 2002. Accepted 30 September 2002. or fast becoming so (M. Bingham, pers comm; G. Mickels Kokwe, pers comm). As a consequence, traders are travelling further afield in order to meet a growing demand.

In south-western Tanzania, members of the Nyamwanga, Nyika, Nyiha, Fipa, Lungu and Ndali groups have also traditionally harvested orchid tubers, and eaten a similar dish known in Kiswahili as Kinaka. Leedal (1975) reported that Disa robusta and species of Satyrium and Habenaria were eaten in the Southern Highlands, and Cribb \& Leedal (1982) documented that tubers of Satyrium buchananii were eaten in times of famine. As in Zambia (Bingham, 2000), traditional harvesting probably did not threaten orchid populations but orchid collection in Tanzania seems to have increased markedly over the past few years.

There are parallels with the Turkish trade in salep, ground orchid bulbs from 30 species used as a medicine, a drink and as a binder in ice cream (Kasparek \& Grimm, 1999). Between 10 and 20 million tubers are harvested annually in Turkey (Read \& Groves, 1994) for export across Europe, and the implications for orchid conservation have been widely investigated (Gasser, 1994; Read \& Groves, 1994; Kasparek \& Grimm, 1999).

In this paper we document for the first time the growing commercial trade in Tanzanian orchids from across the Southern Highlands. This trade has arisen because of an escalating demand in Zambia and not 
because of domestic consumption, which may be diminishing. We make preliminary estimates of the scale of harvesting and the species involved, describe harvesting and trade dynamics, make comparisons with the salep trade, and present some recommendations for conservation action. We conclude that the trade, largely unknown outside the area, poses a serious risk to many orchid species across southern Tanzania, particularly to those with a restricted distribution.

\section{Study area}

The Southern Highlands lie between $7^{\circ}$ and $10^{\circ}$ south, and $31^{\circ}$ and $35^{\circ}$ east in the administrative regions of Iringa, Mbeya and Rukwa. They rise to 2,961 m altitude and include the Kipengere Range, Uporoto, Umalila, Livingstone Mountains, Njombe Highlands, Mount Rungwe, Mbeya Range, Kitulo Plateau and the Ufipa Plateau (Fig. 1). Protected areas are limited to a number of forest reserves mostly gazetted for their catchment or production qualities. Most of the montane grasslands have no protection status, although there are proposals to gazette parts of Kitulo Plateau as a National Park. The region is large and ethnically diverse (Fig. 1), with high human population density and correspondingly intense agricultural activity.
Dominated by species of Andropogon, Eragrostis, Hyparrhenia, Pennisetum and Setaria, the fire-climax montane grasslands of the Southern Highlands remain largely unexplored biologically, although initial surveys indicate that they are rich, with a diverse array of rare and restricted-range species (Davenport, 2000). Whilst there are endemic species in many biological groups, the floral diversity is most conspicuous, with more than 2,000 species of vascular plants known from the area (Gereau \& Kajuni, in press). Many species are endemic to the Southern Highlands, and a greater number are restricted to the Highlands and the Nyika Plateau in Malawi. The block-faulted Uporoto, the volcanic Rungwe and Mbeya, and the older metamorphic Kipengere Range all give rise to distinct botanical assemblages. The Kitulo Plateau however, has long been recognized as an area of outstanding botanical importance (Elton \& Cotteril, 1879; Gilman, 1927; Greenway, 1955; Hedberg, 1957; Summerhayes, 1968; Cribb \& Leedal, 1982; Lovett, 1990, 1993; Rodgers, 1993; Lovett \& Prins 1994; Lovett et al., 1995, Mwasumbi, 1999; Ndangalasi, 1999; Davenport \& Moyer, 2000).

The majority of montane grassland species are perennial geophytes, including a significant number of terrestrial orchids. At least 31 species are national endemics, with 16 endemic to Kitulo and Kipengere and 10 restricted

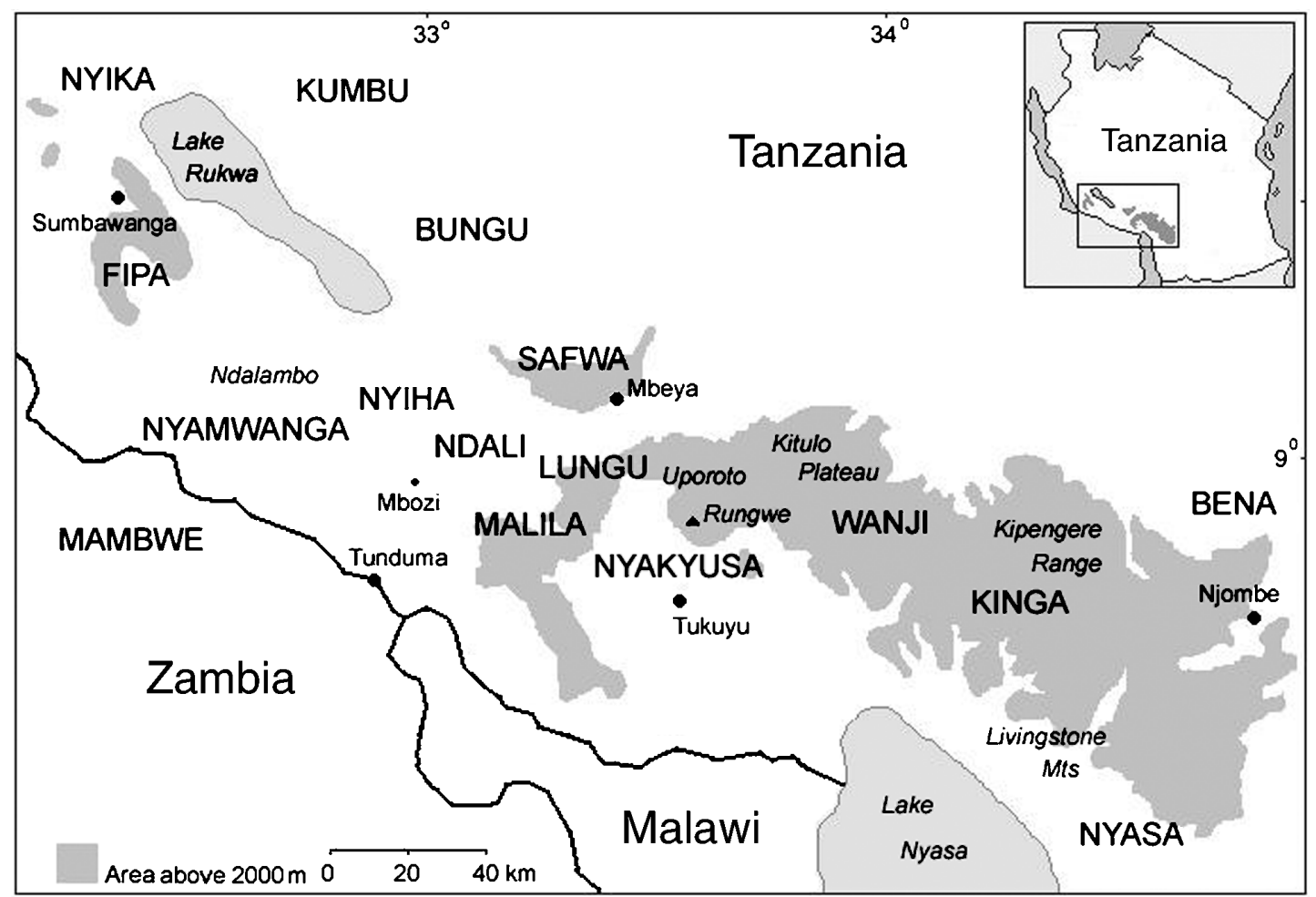

Fig. 1 The Southern Highlands of Tanzania, shaded, illustrating orchid collecting sites and the approximate distribution of the main ethnic groups (in uppercase). 
to Kitulo and Uporoto (Lovett \& Prins, 1994; Lovett et al., 1995, Mwasumbi, 1999; Ndangalasi, 1999; Gereau \& Kajuni, in press). Upland grasslands have been described as the true relict community of the Afromontane region, and it is probable that the Southern Highlands represent an important centre of endemism for high altitude species (Kingdon, 1990).

The Orchidaceae is a family of epiphytic or terrestrial non-woody perennials with more than 20,000 species worldwide. Because of the poor knowledge of their distributions many species do not appear on global Red Data lists (SABONET, 2000), although all orchids are listed in Appendix II of the Convention on International Trade in Endangered Species (CITES), which requires certification of all plants (and related material) crossing international borders (Kasparek \& Grimm, 1999). The three Tanzanian genera harvested for human consumption are terrestrial. Disa is a large African genus with at least 15 species in the Southern Highlands (Cribb \& Leedal, 1982; Lovett et al., 1995; Gereau \& Kajuni, in press). Many are restricted to small areas; e.g. Disa longilabris is endemic to Kitulo Plateau and Njombe, and D. ukingensis is known only from Kitulo and the Nyika Plateau. Satyrium species are found in temperate and montane Africa, and of c. 90 species at least $25 \%$ occur in the Southern Highlands, including S. monadenum known only from Mount Rungwe and Kitulo (Cribb \& Leedal, 1982; Gereau \& Kajuni, in press). Habenaria is a large pan-tropical genus, with at least 52 species occurring in the Southern Highlands (Summerhayes, 1968), almost half of the East African total (Cribb \& Leedal, 1982).

\section{Methods}

Data collection was initiated in May 2000. Field data were gathered by observation of collectors, traders and brokers, both in the field and at the main market in the border town of Tunduma, and by informal interviews with collectors, traders, brokers and village leaders across the region. In total 60 individuals were interviewed or consulted about orchid harvesting and trade. Whilst interviews were conducted in Kiswahili, vernacular names for orchid varieties were also documented in nine local languages.

Interviewees were questioned in a manner consistent with their involvement or knowledge of the trade. Data were collected on interviewees' age, sex, ethnic background, as well as on collecting sites and seasons, destination of tubers (domestic or commercial use), prices at different points of sale, storage techniques, transport employed and routes taken, volumes harvested per collecting day and orchid varieties harvested. Collectors were asked how long they had been involved in harvesting, and whether they had noticed any significant changes in tuber availability, either in terms of volumes harvested or distances walked to reach suitable collecting sites. Traders and brokers in Tunduma were questioned on tuber origins, price fluctuations, preferences for orchid varieties and the dynamics of trade transactions with Zambian buyers. Residents from across the region with knowledge of orchids or the orchid trade were questioned about the perceived availability and distribution of orchids in the region.

Interviews were conducted in the following areas: Magamba (Mbozi district, Mbeya region) in December 2000, Izumbwe, Ibaba, Iwiji (Mbeya rural district, Mbeya region), Kikondo, Matamba, Ujuni and Kinyika (Makete district, Iringa region) in June 2001, Kinyika, Kikondo Itweli, Kikondo Usalama, Mpangala, Ujuni, Kitulo Plateau and Matamba (Iringa region) in June and July 2001, and Mbeya town and Loleza in July 2000. Visits were also made to Tunduma (Mbeya region) in July and December 2001.

In order to make an approximate estimate of the amount of orchids passing through Tunduma each year, traders and brokers were questioned as to the number of sacks of tubers sold across the border per day, both in the low and high seasons. Additionally, fourteen debes (a debe being a tin with a volume of 18-20 litres) were selected at random and the number of tubers in each debe were counted.

\section{Results}

The results from the interviews and direct observations in the field and in Tunduma indicated that there is a thriving trade in Tanzanian orchid tubers across the Southern Highlands. Thirty different names for various orchid 'types' from nine ethnic groups in the area were documented (see also Davenport \& Ndangalasi, 2001), with the generic terms for orchid tubers being Chikanda (Fipa, Nyamwanga), Finaka (Malila), Finsekeni (Kinga, Nyakyusa, Wanji), Kikanda (Safwa), Kikande (Ngoni), Kinaka (Nyiha), Mansekeni (Kinga), Ngulingusi (Wanji) and Vinaka (Nyiha, Safwa).

There was no evidence of any people eating Kinaka outside Mbozi (Nyiha) or Sumbawanga (Fipa), and one individual from the Lungu group claimed that his relatives no longer ate it. Many people amongst the Nyiha and Fipa alleged that the younger generations from both areas no longer eat it as much as their elders, if ever, indicating a decline in domestic consumption. One Nyiha woman who has been harvesting tubers for 5 years acknowledged that whilst some of her relatives still eat Kinaka, she collects only for export because the domestic market is not large enough.

All the collectors interviewed stated that they were collecting for the Zambian market and that most tubers 
are exported through the border town of Tunduma. However, some trade was observed during this study taking place from Sumbawanga southwards through Tatanda and thence into Zambia. It was claimed that there is no trade directly from Tanzania into Malawi, although this could not be confirmed.

According to the collectors interviewed, 'edible' orchids grow primarily in areas without cultivation, usually on hillsides and montane grasslands or areas that have not been farmed for some time. Some species are occasionally collected from areas that have lain fallow for more than than 3 years, or more rarely from low-lying areas such as the foot of hills and plateaux. Whilst tubers are collected wherever they grow, a current focus of collecting activity was reported to be on and around the Kitulo Plateau. Here the collectors (some from Mbozi and Zambia and who stayed in the area for several weeks) were aware that all activities within the state-managed farm on the plateau are prohibited, but the high price of tubers was deemed to obviate the risk. Elsewhere, collectors stated that in Sumbawanga tubers are collected from the extensive Mbizi grasslands on the Ufipa Plateau, whereas around Mbeya region harvesting is carried out on the flanks of the Mbeya Range, in Uporoto and in Umalila.

Some traders who buy directly from villages claimed that in order to keep up with demand they are now venturing further afield and cited Mufindi, Njombe and Sao Hill as new collection sites. Traders in Tunduma reported that tubers are usually categorized and priced according to their origin, with four principal areas, listed here in decreasing order of the value attributed to their orchids: 1) Sumbawanga (Ufipa Plateau); 2) Iringa/ Mbeya (Kitulo Plateau, Njombe, Imalilo, Kipengere, Mufindi, Dabaga and Ibaga); 3) Ndalambo (the plain between Tunduma and Sumbawanga); 4) Mbeya (Mbeya Range, Umalila and Uporoto).

Whilst some regional and cultural variation was noted, tuber collection was observed to be carried out by men and women, young and old. It was generally considered a part-time occupation carried out only in order to supplement income from cash crops and farming. There was a consensus from all areas as to the collection procedure. Once the aerial shoot of the orchid has been located, soil is removed with a hoe and the tuber extracted. Harvesting continues until all tubers in the locality have been collected, and this is repeated each year, especially where tuber density is high. After 3-4 years, however, collectors stated that plant succession is greatly affected, with habitats initially dominated by grasses replaced by shrubby vegetation with a concomitant reduction in orchid numbers.

Collectors stated that an agreement on the price to be paid per unit volume is usually reached with a local trader prior to harvesting. Prices ranged between 2,000 and 5,000 TShs (Tanzanian Shillings) (US \$2.50-6.25) per sack, equivalent to 5-6 debes. The variation was attributed to tuber availability in the field. The harvesting season varied slightly from area to area, but collection was widely cited as starting at the end of February and continuing until late November prior to the onset of the rains. Collectors reported that from February to May fresh plants can still be observed, but during the dry season from June the aerial parts dry and die away and fires burn much of the relevant habitat. However, collectors stated that they can still locate tubers by tracing remnants of the aerial shoot even after burning.

Collectors explained that tubers are brought down from the mountains by foot or on donkeys, and local traders use a potato or pyrethrum lorry for transport to Tunduma. Most traders stated that they use polythene bags that can accommodate as much as 200 litres (normal sacks contain a maximum of 120 litres). Because officials at village or government checkpoints charge taxes per sack (and not per unit weight) this maximizes profits. This is also the same for transportation costs, as the criterion is the sack and not unit weight. The amount of sacks carried during one trip was quoted as generally varying between one and 10, although in some cases as many as 20 sacks were carried. The cited reasons for the differing volumes transported were price, tuber availability, time of year, capital available and transport reliability. Costs for the whole trip to Tunduma were cited as a maximum of 6,000 TShs (US \$7.50) per sack.

No interviewees had performed trials to propagate orchids, although collectors and traders were aware that when one tuber is planted it produces only one tuber at the end of the season due to the existence of only one lateral bud on an orchid tuber. The only difference observed was that if tubers grow in more fertile soil, and free from competition with weeds, the resulting bulb is larger. There was no perceived incentive for cultivating orchids, and it was considered easier and more economical to harvest wild populations.

Without exception collectors stated that orchids are becoming more scarce, with greater distances covered and more effort needed to locate tubers in the field. One collector in Ujuni claimed that 10 years ago it used to take 30 minutes to reach most of the good harvesting areas, whereas today it takes at least 5 hours to reach suitable sites. Traders from Songea reported that they have recently started bringing tubers from Ruvuma, and collectors began harvesting in Njombe in 1999. The main reasons put forward to explain this trend were an increase in the number of collectors and traders, an increase in land under cultivation (especially for potatoes and pyrethrum), and over-harvesting. Whilst 
the latter is linked to the number of collectors, it was recognized that individuals are taking more tubers and spending more time harvesting because of the high financial rewards.

Sale of tubers at Tunduma was observed to take place using brokers. Such individuals were used in order to facilitate communication with Zambian customers, provide office and storage space, and to assist with currency transactions. However, in the low season traders do sell directly to Zambians. Both traders and brokers claimed that they can identify inedible tubers $(\operatorname{mad} u d u)$ even if purposefully mixed with edible varieties. Tanzanian traders stated that they were reticent to cross the border themselves to sell. Whilst profits of up to $100 \%$ can and have been made, trips were only worthwhile with large volumes, and as there was always a risk of loss, sale to Zambians at the border was preferred.

The price of tubers in late March 2001 in Tunduma was about TShs 20,000 (US \$25) per sack. This was the period when tubers were abundant from all three main areas. By June supplies had begun to dwindle and prices had risen. The average price per sack in June 2001 was TShs 45,000 (US \$56.25), although traders predicted that towards the end of the dry season the price would rise further to TShs 90,000 (US \$112.50).

According to collectors and traders, all orchid tubers can be stored whilst waiting for better prices, and will last for 6 months or more in suitable conditions. In Tunduma, tubers were observed mixed with moist soil to avoid shrinking, and spread out in a closed storage room floor to avoid sunlight, which initiates re-sprouting. Storage can be a problem in Tunduma, because the tubers originate from areas that are much cooler. As re-measurement is carried out in the process of selling, loss of volume by shrinkage was reported to be an important consideration. Traders claimed that long-term storage can result in a loss of $16-20 \%$, and as a consequence brokers stated that they will not pay traders from the villages unless there are Zambian customers already present. Traders must wait for customers, and receive payment only after the tubers have been re-measured. More often, traders are advised to store the tubers in the villages and to take them to Tunduma when they are assured of an immediate sale.

The volumes harvested varied seasonally and from area to area. In villages near Kitulo, for example, one individual reported collecting one debe per day from February to April, when tubers are most abundant. From June to November however, tubers are in short supply and collectors stated that they needed at least one week to collect the same amount. During the high season in Mbeya a collector can average half of one debe per day but required 10 days for the same amount at other times.
Fourteen debes in July 2001 contained 400, 406, 411, 413, 414, 419, 423, 424, 428, 432, 434, 435, 445 and 453 tubers, and 5-6 debes per sack were recorded. In the high season in Tunduma traders and brokers asserted that at least 10 sacks per day are sold, and four sacks per day in the low season. Thus in a high season of 3 months, with a minimum of 400 individual tubers per debe, c. 22,000 individual tubers are sold each day, giving 1,584,000 for 12 6-day weeks. In a low season of 3 months, c. 8,800 are sold per day, giving 633,600 for 12 6-day weeks. Thus an approximate minimum total of 2,217,600 tubers pass through Tunduma each year. Given that the harvesting season is usually 10 months rather than 6 , and with a maximum of 453 tubers per debe, the volume being exported to Zambia through Tunduma each year may be as high as 4,185,720 tubers. Taking into account the volumes exported in different seasons and the differing prices per sack in Tunduma, the business in Tunduma alone is probably worth 100-200 million TShs per year, equivalent to US $\$ 118,000-235,000$ per year.

\section{Discussion}

The harvesting of terrestrial orchid tubers from the grasslands of Tanzania's Southern Highlands is not a recent phenomenon, but the magnitude of the harvest and the extensive international trade are. Quantifying the trade and the numbers of orchids harvested was problematical. The length of the harvesting season varies and the varieties sold at market differ in size and abundance at different times of the year. For the purposes of this study, therefore, figures were based on data gathered from the market at Tunduma. In all instances, however, conservative estimates were used in the calculations, and they compared favourably with the approximate amounts harvested at village level. This study shows that between approximately 2.2 and 4.1 million orchid plants now leave Tanzania each year for consumption in Zambia, at an approximate value of nearly a quarter of a million \$US per year.

It was difficult to determine precisely which species of Disa, Satyrium and Habenaria were being collected because harvesting occurs mainly in the dry season, when the flower has already withered. Although we investigated local descriptions and tuber identifications, indigenous classification systems usually evolve from direct use of plants and animals and thus do not necessarily consider a 'species' or 'genus' but rather a group of organisms with similar uses and traits. Thus tubers harvested may have the same or similar names for different species or genera, and vice versa. It also remains unclear how many species are considered edible 
and are thus harvested. However, at least 85 species from these three genera are known from the Southern Highlands (Summerhayes, 1968; Cribb \& Leedal, 1982; Lovett et al., 1995; Gereau \& Kajuni, in press). If all species from these genera are suitable (as maintained for all Zambian species by Bingham, 2000), then as many as 85 species of terrestrial orchid may be harvested in the Southern Highlands. It remains to be seen whether other genera are also edible.

According to residents, many parts of Ufipa Plateau and Mbeya have already lost their wild orchids and all collectors reported having to forage further afield each year. Collectors stated that they are now searching new sites such as Dabaga, Mufindi, Njombe and Songea. Demand is growing but local supplies appear to be rapidly dwindling. Based on this, the experience in Zambia (Bingham, 1999, 2000), and the current scale and techniques of collection, it is likely that this trade is unsustainable.

It appears that collection in the Southern Highlands is almost exclusively for the Zambian market, and that compared with the volume of tubers passing across the border, consumption in Tanzania is low. Clearly there are parallels with the salep trade in Turkey, where an estimated 10-20 million orchids are harvested each year (Read \& Groves, 1994), although from a far larger area than Tanzania's Southern Highlands. In the past decade however, substitutes have been increasingly used and there has been a marked decrease in the collection of Turkish orchids (Gasser, 1994; Kasparek \& Grimm, 1999), and the current figure is therefore probably much lower. More importantly in terms of conservation, Kasparek and Grimm (1999) showed that in Turkey only 16 of the 30 harvested species are sensitive to habitat alteration and only one of these is endemic. Furthermore, Turkish collectors harvest only when the plants are in flower and when densities are high, giving the opportunity for orchid populations in many areas to recover (Kasparek \& Grimm, 1999). In Tanzania there are many more orchid species of restricted distribution and all edible plants seen by collectors are harvested. The effects on individual species are thus potentially far more severe.

Although all orchid species are listed in Appendix II of CITES none of the plants currently being exported to Zambia are being registered. Currently the nearest CITES office is in Dar es Salaam, over $850 \mathrm{~km}$ away. Discussions are currently underway with government authorities to address this issue. In February 2002 the Government of Tanzania announced plans to gazette Kitulo Plateau as a National Park. Undoubtedly this will greatly assist the conservation of Tanzania's orchids, although the current intense harvesting pressure on the plateau will necessitate prompt and effective management if many of the new Park's most important assets are not to be lost. Furthermore, orchids are being harvested from grasslands across the Southern Highlands, most of which are outside protected areas.

There are Tanzanians who are making money from this trade, and their interests must be considered. This is particularly so for the collectors at village level for whom orchid tubers represent an additional source of income. Intervention may affect livelihoods, and so any action must be appropriate and sensitive. However, the number of people involved, although growing, is still small. Moreover, it is probable that this income is temporary and unsustainable, and if management is not forthcoming, the resource, and thus the revenue from it, will very soon be depleted anyway. Whilst the monetary value of the trade is significant, it does not compare with the potential revenue from tourism.

The Southern Highlands are currently losing significant numbers of orchids, and at an alarming rate. This has major implications for the conservation of the country's biodiversity as well as for plans to boost national and regional economies through tourism. The current trade in orchid tubers for consumption in Zambia not only contravenes CITES regulations, but is neither environmentally nor economically in the best interests of Tanzania. All evidence indicates that the trade is escalating, with new areas being harvested to meet a growing demand across the border.

In order to combat what may soon become a serious conservation problem, immediate action is critical. Further research is needed to assess the scale and growth of the trade, the distribution of species most at risk, and to provide a baseline for a simple yet robust monitoring system. Furthermore, the Government of Tanzania must be supported to investigate effective management solutions, possible substitutes or propagation technologies, as well as to examine CITES implementation and the feasibility of introducing quotas, licences and harvesting seasons. Without prompt management it is our assertion that many Tanzanian orchids across the south of the country will be seriously threatened from this little known but rapidly escalating international trade.

\section{Acknowledgements}

This work was funded by the Wildlife Conservation Society through the Southern Highlands Conservation Programme. We would like to thank the following for information and advice: Mike Bingham, Colin Congdon, Daniela De Luca, Ezekiel Dembe, Guni Mickels Kokwe, Jon Lovett, Simon Milledge, David Moyer, Joanne Moyer, Josephine Mremi, Alan Rodgers, Godfrey Sanga, Issai Swai and the Tanzanian Ministry of Natural Resources and Tourism. Particular thanks are extended to Felix Amandus, Nicholas Ntinda, Y. M. Solloo, the many individuals 
who gave their time to answer questions, and two anonymous referees for their constructive comments on an earlier draft of this paper.

\section{References}

Bingham, M. (1999) Chikanda. http:/ / www.lowdown.co.zm [accessed 8 November 2002]

Bingham, M. (2000) Notes on Zambia's Threatened Plants. Southern African Plant Red Data List Project. http:/ / www.sabonet.org [accessed 8 November 2002] Cribb, P.J. \& Leedal, G.P. (1982) The Mountain Flowers of Southern Tanzania. A.A Balkema, Rotterdam, Netherlands.

Davenport, T.R.B. \& Moyer, D.C. (2000) The Conservation and Management of Kitulo Plateau. Unpublished Report, Wildlife Conservation Society, Tanzania.

Davenport, T.R.B. (2000) Conservation of Montane Grasslands in the Southern Highlands of Tanzania. Unpublished Proposal to UNDP/GEF, Wildlife Conservation Society, Tanzania.

Davenport, T.R.B. \& Ndangalasi, H.J. (2001) Orchid Harvest An Assessment of the Harvesting and Trade of Orchid Tubers Across Tanzania's Southern Highlands. Unpublished Report, Wildlife Conservation Society, Tanzania.

Elton, J.F. \& Cotteril, H.B. (1879) Travels and Researches among the Lakes and Mountains of Eastern and Central Africa. London, UK.

Gasser, M. (1994) Vergleich von Orchideenvorkommen des Kantons Aargau und der Provinz Kastamonu (Turkei). Mitteilungen der argauischen naturforschenden Gesellscahft, 34, 95-120.

Gereau, R.E. \& Kajuni, A.R. (in press) Lake Nyasa Climatic Region Floristic Checklist. Missouri Botanical Garden, Missouri, USA.

Gillman, C. (1927) South-West Tanganyika Territory. Geographical Journal, 69, 96-31.

Greenway, P.J. (1955). Ecological observations on an extinct East African volcanic mountain. Journal of Ecology, 43, 544-563.

Hedberg, O. (1957) Afroalpine vascular plants; a taxonomic revision. Symbolae Botanicae Uspaliensis, 15, 1-411.

Kasparek, M. \& Grimm, U. (1999) European trade in Turkish salep with special reference to Germany. Economic Botany, 53, 396-406.

Kingdon, J. (1990) Island Africa. The Evolution of Africa's Rare Animals and Plants. Collins, London, UK.
Leedal, G.P. (1975) Useful Plants of the Southern Highlands of Tanzania. Unpublished Report, Mbeya, Tanzania.

Lovett, J.C. (1990) The Kitulo Plateau. Swara, 13, 11-12.

Lovett, J.C. (1993) Temperate and tropical floras in Tanzania. Opera Botanica, 121, 217-227.

Lovett, J.C. \& Prins, E. (1994) Estimation of land-use changes on Kitulo Plateau, Tanzania, using satellite imagery. Oryx, 28, 173-182.

Lovett, J.C., Gereau, R.E. \& Sidwell, K.J. (1995) Vegetation and Phytogeography of the Kitulo Plateau, Southern Tanzania.

Proceedings of the XIIth AETFAT Congress, Zomba, Malawi.

Mwasumbi, L.B. (1999) Highlights of the Vegetation Cover of Kitulo Plateau, Makete District. Unpublished Report, University of Dar es Salaam, Tanzania.

Mwizenge, S.T. (1997) Chinaka - Traditional Food of the Tumbuka people of Zambia. http:/ / www.bridgewater.edu/ mtembo/ chinaka [accessed 8 November 2002]

Ndangalasi, H.J. (1999) Kitulo Plateau: An Area of Biodiversity Importance. Unpublished Report, WCST Dar es Salaam, Tanzania.

Read, M. \& Groves, M. (1994) Wilde Orchideen in der Eistute. $B B C$ Wildlife Magazine, 5, 6 .

Rodgers, W.A.R. (1993) Conserving small areas in Tanzania, Kitulo Plateau. In Protected Area Planning for Biodiversity Conservation, Field Document 4, UNDP/FAO/GEF.

Summerhayes, V.S. (1968) Orchidaceae Part I. In Flora of Tropical East Africa (eds E. Milne-Redhead \& R.M. Poltill). Crown Agents, London, UK.

SABONET (2000) Southern African Plant Red Data List Project. http://www.sabonet.org/reddatalist/index.html [accessed 14 October 2002]

\section{Biographical sketches}

Tim Davenport is the Director of the Southern Highlands Conservation Programme, a project of the Wildlife Conservation Society, based in Mbeya, south-west Tanzania. He has spent the last decade working in conservation in Uganda, Cameroon and Tanzania.

Henry Ndangalasi is a botanist currently studying the implications of using non-timber forest products in mountain ecosystems, and has worked in numerous conservation and botanical projects throughout Tanzania. 